\title{
Relationship between the relaxation time distribution function from IP Effect's Dias model and petrophysical parameters of reservoir rock samples
}

Maria R. L. Carvalho', Leonardo P. Marinho', Carlos A. Dias', Alexandre N. Barreto², Victor H. Santos'

${ }^{1}$ UENF - Universidade Estadual do Norte Fluminense; ${ }^{2}$ IFF - Instituto Federal Fluminense

Copyright 2019, SBGf - Sociedade Brasileira de Geofísica

This paper was prepared for presentation during the $16^{\text {th }}$ International Congress of the Brazilian Geophysical Society held in Rio de Janeiro, Brazil, 19-22 August 2019.

Contents of this paper were reviewed by the Technical Committee of the $16^{\text {th }}$ International Congress of the Brazilian Geophysical Society and do not necessarily International Congress of the Brazilian Geophysical Society and do not necessarily represent any position of the SBGf, its officers or members. Electronic reproduction or storage of any part of this paper for commercial
of the Brazilian Geophysical Society is prohibited.

\section{Abstract}

The determination of petrophysical rock parameters from the induced polarization effect, registered in spectral resistivity measurements, has been gaining prominence in the international geophysical scenario. Among the electric models that can describe the IP effect, the wellknown Dias model has obtained excellent results. In recent studies, this model equally makes it possible to carry out estimates of petrophysical properties of rocks containing disseminated clay or metallic minerals. However, in specific cases of rocks with high heterogeneities, it is suggested the application of a composed model (Dias/Cole-Cole). Rewriting the cited models in terms of partial fractions, it was possible to establish a function that describes the relaxation times distribution from measurements of spectral electrical resistivity and, consequently, the pore/throat sizes distribution of reservoir rock samples from two Brazilian oil producing basins.

\section{Introduction}

Induced polarization (IP) is one of the electrical geophysical methods that has become increasingly important in the petroleum industry due to its ability to characterize hydraulic properties and to map the distribution of fluids in the subsurface (Lima \& Niwas, 2000; Vickery \& Hobbs, 2003). This effect is characterized by the storage of electric charges in the porous media through electrochemical connections (Marshall \& Madden, 1959).

In recent years, a great advance has been made in studies using the IP method to find correlations between parameters of induced electric polarization and the textural and hydraulic parameters of rocks (Dias, 2000; Lima \& Niwas, 2000; Slater \& Lesmes, 2002; Binley et al., 2005; Tong et al., 2006a,b; Börner, 2006; Revil \& Florsch, 2010; Jougnot et al., 2010; Koch et al., 2012; Barreto \& Dias, 2014; Marinho \& Dias, 2017; Marinho et al., 2018).

Dias (2000) has demonstrated that experimental data of complex resistivity can be adjusted adequately through the Dias model in the whole spectrum of frequencies in which the induced polarization effect occurs. The existence of several phase maxima related to different processes of the rock-fluid interaction (Dias, 2000; Capaccioli et al., 2001; Barreto \& Dias, 2014), due to formation of the electrical double layer at the clayelectrolyte interface, has required optimized electrical models for different cases, aiming at correct description of the observed IP effect. In this context, the Dias/Cole-Cole composed model becomes useful for describing the intermediate spectrum of frequencies for complex resistivity, related to the heterogeneities in porous media.

From the modeled complex resistivity curves, the parameters obtained from the Dias model allow to determine petrophysical rock properties, such as permeability and mean pore radius (Barreto \& Dias, 2014; Marinho \& Dias, 2017; Marinho et al., 2018). Among the physical parameters that can be obtained from the Dias model, we highlight the characteristic relaxation times main values entering in the phase spectrum construction dominated by IP effect. Morgan \& Lesmes (1994) presented that, knowing the distribution of relaxation times, not only its main value, makes possible the correlation between these relaxation times and other porous media properties distribution.

This study uses the decomposition of the complex resistivity function from Dias model in terms of partial fractions introduced by Barreto \& Dias (2014), as well as the composed model, in order to determine the relaxation times distribution function curves obtained from electrical resistivity data of reservoir rocks samples from the Campos and Recôncavo basins. The introduction of an expression by Marinho (2018) that operates on the distribution function allowed to obtain the pore/throat radius size curves for each rock specimen.

\section{Dataset}

In this study we used a set of experimental data of electrical resistivity composed of siliciclastic rock samples from reservoirs of two Brazilian basins: four samples from Recôncavo Basin (RB), in Northeastern Brazil, with electrical measurements performed by the authors in the range of frequency where the IP effect occurs $\left(10^{-3} \mathrm{~Hz}\right.$ to $10^{5} \mathrm{~Hz}$ ); and data of four samples from Campos Basin (CB), in Southeastern Brazil, from the work of Marinho et al. (2018). The rock sample dataset of the two basins was adjusted by the Dias and Composed models. It was making possible to identify the characteristic relaxation times of each sample and, later, to determine their respective distribution curves, in terms of relaxation time and pore/throat radius. In addition, for the rock samples from the Recôncavo Basin, the mineralogical characterization was performed by X-ray diffraction and petrographic studies, in order to obtain information about the clay minerals and to assist in the interpretation of collected electrical data. 


\section{Method}

\section{Dias model and Composed model}

The Dias model used to describe the induced polarization effect is defined as a frequency function $(\omega=2 \pi f)$ and dependent on five primitive parameters $\left(\rho_{0}, m, \tau, \eta, \delta\right)$ :

$$
\frac{\rho^{*}-\rho_{\infty}}{\rho_{0}}=\frac{m}{1+i \omega \tau^{\prime}(1+1 / \mu)}
$$

where $i^{2}=-1, \tau^{\prime}=[(1-\delta) /(1-m) \delta] \tau, \mu=i \omega \tau\left[1+\eta(i \omega)^{-1 / 2}\right]$ and $\rho_{\infty}=(1-m) \rho_{0}$. The terms $\rho_{0}$ and $\rho_{\infty}$ are values of $\rho^{*}$ when $f \rightarrow 0$ and $f \rightarrow \infty$, respectively; $m$ is the chargeability (dimensionless); $\tau$ is the relaxation time $(s)$ related to the Helmholtz's electrical double layer zone; $\eta$ is the electrochemical parameter $\left(s^{-1 / 2}\right) ; \delta$ is the fraction of unit cell extension affected by polarization effect due to the solid-liquid interface (Dias, 2000).

The Dias/Cole-Cole composed model, present in works such as Marinho \& Dias (2017) and Marinho et al. (2018), aims to perform a better adjustment to experimental data in the intermediate region of the frequency spectrum, where the Dias model, in general, does not get a good fit. The composed model is defined by the following approximate expression, as a frequency function:

$$
\frac{\rho^{*}-\rho_{\infty}}{\rho_{0}}=\frac{m_{W 1}}{1+\left(i \omega \tau_{W 1}\right)^{1 / 2}}+\frac{m_{D}}{1+i \omega \tau_{D}}+\frac{m_{W 2}}{1+\left(i \omega \tau_{W 2}\right)^{c}},
$$

where $m_{W}, m_{W 2}$ and $m_{D}$ are partial chargeability associated, respectively, to the low, intermediate and high frequencies of the observed spectrum. The partial chargeabilities relate to original Dias model chargeability $(m)$ through the relationship: $m \approx m_{W 1}+m_{W 2}+m_{D}$. The expression (2) is also dependent on three distinct main relaxation times. According to Barreto \& Dias (2014), $\tau_{W}$ and $\tau_{D}$ from the original Dias model are related, respectively, to the ionic diffusion process inside the electrical double layer (low frequencies) and to capacitive-resistive effect of this same formed structure (high frequencies). The term $\tau_{W 2}$ is the main relaxation time corresponding to a peculiar diffusion process under influence of heterogeneities of each geological material. The $c$ index, characteristic of Cole-Cole's functions $(0 \leq c \leq 1)$, is related to the intensity of heterogeneities present in the rock-fluid system.

\section{Relaxation time distribution function and its application in the determination of pore/throat size distribution curves}

The relaxation time distribution due to the IP effect can be defined by an infinite series of Debye functions, or as a finite series of Cole-Cole functions, which can be written initially as $g\left(\tau / \tau_{0}\right)$, where $\tau_{0}$ represents the main relaxation time around which other time values are distributed. In this case, the expression of the complex resistivity is given by:

$$
\begin{aligned}
\frac{\rho^{*}-\rho_{\infty}}{\rho_{o}} & =m \int_{0}^{\infty} \frac{g\left(\tau / \tau_{0}\right)}{1+i \omega \tau} d\left(\tau / \tau_{0}\right) \\
& =m \int_{0}^{\infty} \frac{\left(\tau / \tau_{0}\right) g\left(\tau / \tau_{0}\right)}{1+i \omega \tau} \frac{d\left(\tau / \tau_{0}\right)}{\left(\tau / \tau_{0}\right)} .
\end{aligned}
$$

The function (3) can be written, after making changes of convenient variables, such as:

$$
\begin{aligned}
\frac{\rho^{*}-\rho_{\infty}}{\rho_{o}} & =m \int_{-\infty}^{\infty} \frac{G\left(\operatorname{Ln}\left(\tau / \tau_{0}\right)\right)}{1+i \omega \tau} d\left(\operatorname{Ln}\left(\tau / \tau_{0}\right)\right) \\
& =m \int_{-\infty}^{\infty} \frac{G(s)}{1+i \omega \tau} d s,
\end{aligned}
$$

where $s=\operatorname{Ln}\left(\tau / \tau_{0}\right)$.

The relaxation time distribution function for a ColeCole function is defined, according to Cole \& Cole (1941), as:

$$
G(s)=\frac{1}{2 \pi}\left[\frac{\operatorname{sen}[\pi(1-c)]}{\cosh (c s)-\cos [\pi(1-c)]}\right] \text {. }
$$

Comparing the equation (3) with the complex resistivity function (2) written for the composed model, it can be verified that the cited model can be rewritten approximately by the sum of three Cole-Cole functions:

$$
\begin{aligned}
\frac{\rho^{*}-\rho_{\infty}}{\rho_{o}} & =m \int_{-\infty}^{\infty} \frac{\operatorname{FDTR}(s)}{1+i \omega \tau} d s \\
& =\frac{m_{W 1}}{1+\left(i \omega \tau_{1}\right)^{1 / 2}}+\frac{m_{W 2}}{1+\left(i \omega \tau_{2}\right)^{c}}+\frac{m_{D}}{1+i \omega \tau_{3}} .
\end{aligned}
$$

where $\tau_{1}=\tau_{W 1}, \tau_{2}=\tau_{W 2}$ and $\tau_{3}=\tau_{D}$.

Therefore, the relaxation time distribution function can be also represented by equation (7), given by:

$$
\begin{aligned}
\operatorname{FDTR}(s) & =\left.\left(m_{W 1} / m\right) G\right|_{c=0.5, \tau_{W 1}} \\
& +\left.\left(m_{W 2} / m\right) G\right|_{c, \tau_{w 2}} \\
& +\left.\left(m_{D} / m\right) G\right|_{c=1, \tau_{D}}
\end{aligned}
$$

where, again, we have: $m \approx m_{W 1}+m_{W 2}+m_{D}$.

The function obtained in (7) allows us to find the relaxation time distribution and, in turn, allows to relate these times to micro-geometric sizes present in the porous media, if we know the relation between the relaxation time and the pore size scale. Using the equation found by Marinho (2018) for the mean pore/throat radius $r_{p}(\mu m)$ and the relaxation time related to diffusion effect, $\tau_{W 1}(s)$, we have the following expression for each rock sample:

$$
r_{p}=\frac{2 f_{a} \sqrt{\tau_{W 1} D_{c}}}{v(F-1)},
$$


where $f_{a}$ is a factor that measures the influence of ohmic conduction from polarization-free saturated pores on the relaxation time associated with the diffusion effect $\left(\tau_{W 1}\right) ; D_{c}$ is the diffusion coefficient of cation present in the electrolyte; $v$ and $F$ are, respectively, the cementation coefficient and the formation factor of Archie's equation.

\section{Results}

From the observation of the spectral resistivity curves modeled using the Dias model and the composed model (Appendix A), it was possible to obtain the values of the relaxation times distribution functions for each phase maximum registered in the frequency spectrum, which are associated to the functions: Warburg (low frequencies), Cole-Cole (intermediate frequencies) and Debye (high frequencies).

Using the relaxation times found and the function (7), relaxation time distribution curves of the composed model were obtained (Appendix B). With the introduction of equation (8), these were transformed into pore/throat radius size distribution functions for each of specimens analyzed. This appendix presents the set of curves for each sample, comprising graphs concerning: (a) relaxation times distribution curve, with amplitudes given as a percentage of total chargeability from composed model as logarithm to base 10 of the corresponding relaxation times and (b) pore/throat radius distribution function. From the relaxation time distribution curves, we can observe the presence of three functions predicted by equation (7), and which describe processes associated to the induced polarization phenomenon. The first function (Warburg) is associated with the ion diffusion process within the electrical double layer, which has infinite relaxation time values described, approximately, for a low-variance Gaussian. The Debye function describes, with a single relaxation time, the capacitive-resistive effect of the entire electrical double layer, having a Dirac Delta function as its corresponding function. In the region equivalent to the intermediate zone in the frequency domain, there was the presence of a Cole-Cole type function corresponding to a different diffusion process associated with the intensity of the heterogeneity of the rocks. Comparing the set of curves of the two basins, it is sustained that the samples of the Campos Basin exhibit an ion diffusion process inside the more intense electric double layer (red curve) that the samples of the Recôncavo Basin, as well as greater degree of heterogeneity (blue curve).

As there are no experimental measurements of pore radius size to compare with the estimates obtained by the respective distribution function (Appendix $B$ ), it was used for validation the method of Pittman (1992). In this way, it was possible to compare the estimates got by the distribution function with the pore radius intervals using the Pittman's method. Table 1 shows the estimated values for pore radius size for the Campos Basin samples (as a form of validation of this technique) and the samples from the Recôncavo Basin. Observing this Table 1, it is verified that the estimated intervals for the Campos Basin samples cover the respective intervals estimated by the Pittman's method, in agreement with the results obtained by Marinho et al. (2018). On the other hand, the intervals estimated through the function of pore size distribution are lower than the intervals obtained with the Pittman's method in samples from the Recôncavo Basin.

It can be verified from equation (8) that the radius of the pore depends on petrophysical and textural characteristics of the rock. Based on the geological information obtained from Recôncavo Basin sandstones (see Table 1), the presence of calcitic cement could cause a reduction in the cement quality of the grains. This weak cementation, coupled with low grain compaction, possibly influences the measurements of the complex resistivity of these rocks. These geological characteristics could interfere in the resolution of the first phase maximum recorded in the curves of the Recôncavo samples (usually with low resolution). This first peak is essential to obtain a good estimation of the petrophysical parameters using the Dias model. Fortunately, the first phase peak recorded in the spectral resistivity dataset of the two basins was identified with acceptable resolution in most cases and allowed to obtain good quality pore size distribution curves.

Table 1 - Estimates for pore/throat radius size from relaxation times distribution function curves and results from mineralogical characterization performed in laboratory for RB's rock samples.

\begin{tabular}{|c|c|c|c|c|c|c|c|c|c|c|}
\hline Basin & $\begin{array}{c}\text { Sample } \\
\text { ID }\end{array}$ & $\begin{array}{l}\text { Depth } \\
\text { (m) }\end{array}$ & $\begin{array}{c}r_{p} \\
(\mu \mathrm{m})\end{array}$ & $\begin{array}{l}\text { Estimated } \\
\text { range of } r_{p} \\
\text { using the } \\
\text { distribution } \\
\text { function } \\
(\mu \mathrm{m})\end{array}$ & $\begin{array}{l}\text { Estimated } \\
\text { range of } r_{p} \\
\text { using } \\
\text { Pittman's } \\
\text { method } \\
\text { (um) }\end{array}$ & $\begin{array}{c}\text { Clay } \\
\text { minerals } \\
\text { content } \\
(\%)\end{array}$ & $\begin{array}{c}\text { Carbonate } \\
\text { content } \\
(\%)\end{array}$ & \multicolumn{2}{|c|}{$\begin{array}{c}\text { Occurrence of } \\
\text { clay minerals } \\
\text { (\%) }\end{array}$} & \multirow{5}{*}{$\begin{array}{c}\text { Occurrence } \\
\text { of calcite } \\
\text { filling pores } \\
\text { (\%) }\end{array}$} \\
\hline & CB-1 & 2692.2* & $1.5^{*}$ & $0.4-5.5$ & $1.0-4.2^{*}$ & \multirow{4}{*}{ Kaolinite } & \multirow{4}{*}{ Calcite } & \multirow{4}{*}{$\begin{array}{l}\text { Pore } \\
\text { filling }\end{array}$} & \multirow{4}{*}{$\begin{array}{l}\text { Involving } \\
\text { the grains }\end{array}$} & \\
\hline 을 & CB-2 & 2696.8* & $2.6^{*}$ & $0.7-9.5$ & $1.7-7.2^{*}$ & & & & & \\
\hline 胥 & CB-3 & $2700.0^{*}$ & $1.7^{*}$ & $0.5-6.3$ & $1.0-4.5^{*}$ & & & & & \\
\hline & CB-4 & 2717.1* & $1.9^{*}$ & $0.5-7.4$ & $1.2-5.3^{*}$ & & & & & \\
\hline \multirow{4}{*}{ 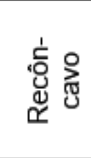 } & RB-1 & 205.5 & 7.6 & $2.0-28.2$ & $13.5-38.4$ & 3.6 & - & 20.0 & 80.0 & - \\
\hline & RB-2 & 206.1 & 1.4 & $0.4-5.0$ & $15.1-34.3$ & 1.8 & - & 15.0 & 85.0 & - \\
\hline & RB-3 & 207.2 & 1.7 & $0.4-6.3$ & $10.3-27.6$ & 0.9 & 5.2 & 40.0 & 30.0 & 30.0 \\
\hline & RB-4 & 207.5 & 2.9 & $0.8-10.7$ & $12.2-33.4$ & 1.4 & - & 30.0 & 70.0 & - \\
\hline
\end{tabular}

*Data from Marinho et al. (2018). 


\section{Conclusions}

The Campos Basin data and the electrical measurements performed on the rock samples from the Recôncavo Basin can be considered a good quality dataset, since good adjustments were made, and, in turn, allowed to obtain the values of the characteristic relaxation times of each rock specimen. Then, the introduction of the concept of distribution function of these relaxation times from the total current resistivity function of the Dias and composed models, allowed to find their corresponding functions pore/throat size distribution with good precision. Furthermore, it was verified that the estimates made for pore size of the Campos Basin samples had intervals very close to the respective intervals estimated by the Pittman's method. In the rock samples from the Recôncavo Basin, the intervals estimated by the distribution function had a lower convergence, possibly due to the interference of the textural aspects of the samples in the spectral record of the electrical resistivity in the laboratory.

\section{Acknowledgments}

We thank LENEP/UENF - Laboratory of Engineering and Exploration of Petroleum - for the excellent infrastructure made available in its petrophysics laboratory. We thank ANP / PETROBRAS for providing the rock samples analyzed here. We are also grateful to PETROBRAS for the funding of this research and to the Brazilian agency CAPES for financial assistance through the granting of a doctoral scholarship to M. R. L. Carvalho, coauthor of this work.

\section{References}

Barreto, A. N. \& Dias, C. A., 2014. Salinity, clay content and permeability of rocks determined through partition fractions decomposition of complex resistivity, Geophysics, 79(5), D333 - D347.

Binley, A., Slater, L. D., Fukes, M. \& Cassiani, G., 2005. Relationship between spectral induced polarization and hydraulic properties of saturated and unsaturated sandstone: Water Resources Res., 41, W12417 / 1-13.

Börner, F. D., 2006. Complex conductivity measurements, in: Groundwater Geophysics - A tool for Hydrogeology, edited by R. Kirsch, 119-153, Springer, Berlin.

Capaccioli, S., Lucchesi, M., Casalini, R. \& Rolla, P.A., 2001. Effect of water inclusions on charge transport and polarization in porous media, IEEE Trans. Dielect. Elect. Insul., 8, 454-459.

Cole, K. S. \& Cole, R. H., 1941. Dispersion and Absorption in Dielectrics I. Alternating Current Characteristics. The Journal of Chemical Physics, 9(4), 341-351.

Dias, C. A., 2000. Developments in a model to describe low-frequency electrical polarization of rocks, Geophysics, $65,2,437-451$.
Jougnot, D., Ghorbani, A., Revil, A., Leroy, P. \& Cosenza, P., 2010. Spectral induced polarization of partially saturated clay-rocks: a mechanistic approach. Geophysical Journal International, 180(1), 210-224.

Koch, K., Revil, A. \& Holliger, K., 2012, Relating the permeability of quartz sands to their grain size and spectral induced polarization characteristics: Geophys. J. Int., 190, 230-242.

Lima, O. A. L. \& Niwas, S., 2000. Estimation of hydraulic parameters of shaly sandstone aquifers from geoelectrical measurements: J. Hydrol.,235, 12-26.

Marinho, L. P. \& Dias, C. A, 2017. Complex resistivity measurements on plugs from Corvina oil field, Campos basin, Brazil. 15th International Congress of the Brazilian Geophysical Society \& EXPOGEF, Rio de Janeiro, Brazil, 31 July-3 August 2017: pp. 929-937.

Marinho L. P., 2018. Estudo do efeito IP observado em amostras de rocha do Campo de Corvina, Bacia de Campos, através de modelos elétricos espectrais. Master Thesis in Reservoir Engineering and Exploration. UENF Universidade Estadual do Norte Fluminense, Macaé-RJ, Brazil, 112pp.

Marinho, L. P., Dias, C. A. \& Santos, V. H., 2018. Determinação de parâmetros de reservatório através do efeito de polarização induzida observado em medidas elétricas espectrais de laboratório. VIII Simpósio Brasileiro de Geofísica - SimBGf, Salinópolis-PA, Brazil, 18-20 September 2018.

Marshall, D.J. \& Madden, T.R., 1959. Induced polarization: a study of its causes, Geophysics, 24(4), 790-816.

Morgan, F.D. \& Lesmes, D.P., 1994. Inversion for dielectric relaxation spectra, J. Chem. Phys., 100, 671681.

Pittman, E. D., 1992. Relationship of porosity and permeability to various parameters derived from Mercury injection-capillary pressure curves for sandstone. AAPG Bulletin, v. 76, n. 2.

Revil, A., \& Florsch, N., 2010. Determination of permeability from spectral induced polarization in granular media: Geophys. J. Int., 181, 1480-1498.

Slater, L., \& D. P. Lesmes, 2002. Electrical-hydraulic relationships observed for unconsolidated sediments: Water Resources Research, 38, 1213.

Tong, M., Li, L., Wang, W., and Jiang, Y., 2006a, A time domain induced-polarization method for estimating permeability in a shaly sand reservoir: Geophys. Prosp.,54, 623-631.

Tong, M., Li, L., Wang, W., and Jiang, Y., 2006b, Determining capillary-pressure curve, pore-size distribution and permeability from induced polarization of shaley sand: Geophysics, 71, N33-N40. 
Vickery, A. and Hobbs, B. A, 2003, Resistivity imaging to determine clay cover and permeable units at an exindustrial site. Vol. 1, No 1, p. 21 - 30.

\section{Appendix A - Electrical dataset from Recôncavo Basin rock samples}

In this appendix, we have represented the electrical resistivity data from the Recôncavo Basin samples measured at the LENEP/UENF's petrophysics laboratory. The experimental dataset from the Campos Basin rock samples, as well as their respective modelled curves, which provided information for the study presented in this expanded abstract, are available in Marinho et al. (2018).

RB-1
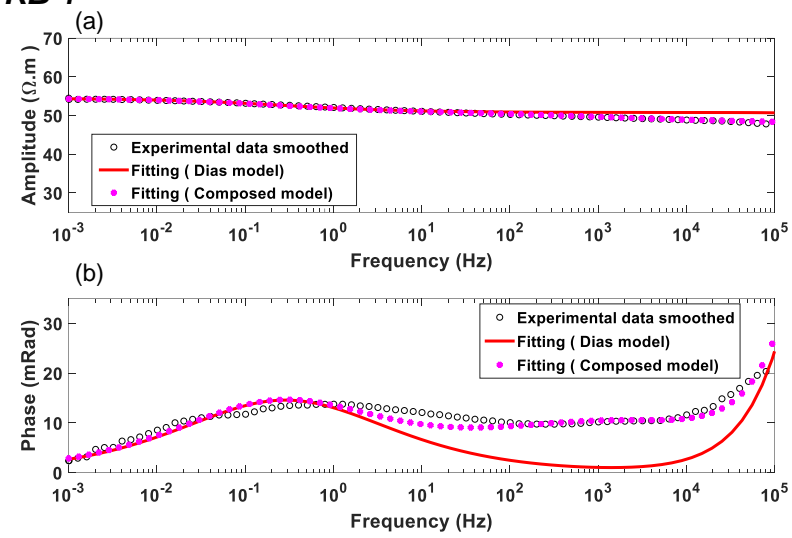

Figure A1 - Experimental data and modeled curves from RB-1 sample: (a) amplitude and (b) phase.

Table A1 - Fitting parameters for RB-1 sample.

\begin{tabular}{|l|l|}
\hline \multicolumn{1}{|c|}{ Dias model } & \multicolumn{1}{c|}{ Composed model } \\
\hline$\rho_{0}=54,5 \Omega m ; m=0,360 ;$ & $\rho_{0}=54,5 \Omega m ; m=0,490 ; \tau=5,7 \times 10^{-7} s ;$ \\
$\tau=6,5 \times 10^{-7} s ;$ & $\delta=0,92 ; \eta=1,38 s^{-1 / 2} ; m_{W 2}=0,057 ;$ \\
$\delta=0,87 ; \eta=1,60 s^{-1 / 2}$ & $\tau_{W 2}=1,1 \times 10^{-4} s ; c=0,38$ \\
\hline
\end{tabular}

RB-2
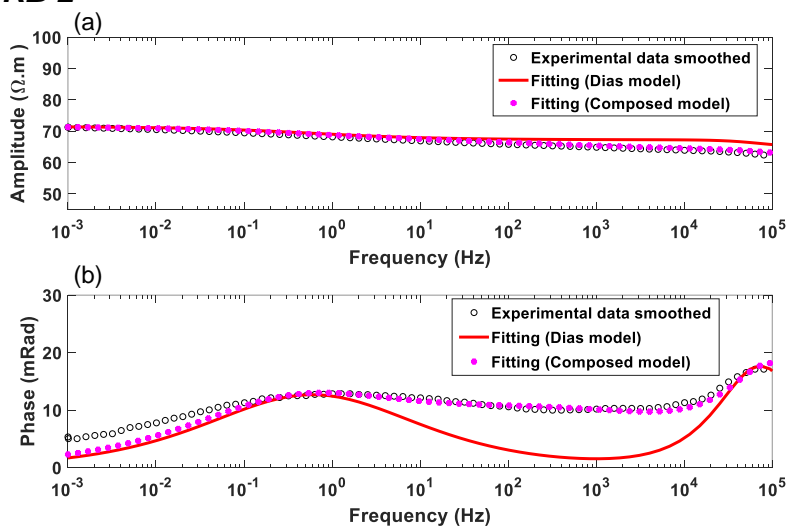

Figure A2 - Experimental data and modeled curves from RB-2 sample: (a) amplitude and (b) phase.

Table A2 - Fitting parameters for RB-2 sample.

\begin{tabular}{|l|l|}
\hline \multicolumn{1}{|c|}{ Dias model } & \multicolumn{1}{c|}{ Composed model } \\
\hline$\rho_{0}=71,5 \Omega m ; m=0,092 ;$ & $\rho_{0}=71,5 \Omega m ; m=0,140 ; \tau=2,4 \times 10^{-6} s ;$ \\
$\tau=3,4 \times 10^{-6} s ;$ & $\delta=0,38 ; \eta=4,20 s^{-1 / 2} ; m_{W 2}=0,075 ;$ \\
$\delta=0,38 ; \eta=5,30 s^{-1 / 2}$ & $\tau_{W 2}=4,5 \times 10^{-4} s ; c=0,29$ \\
\hline
\end{tabular}


RB-3

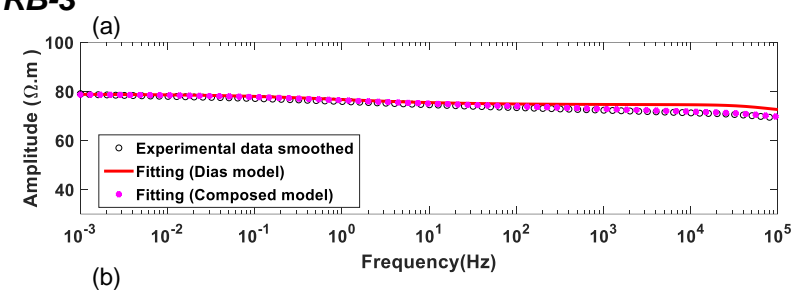

(b)

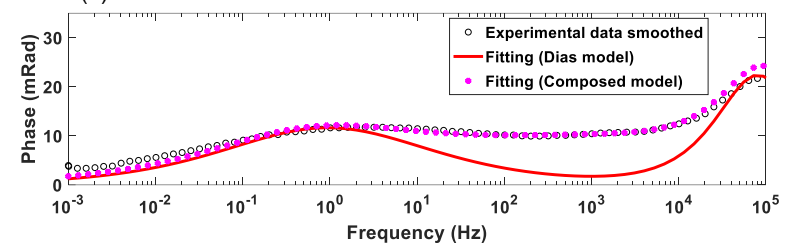

Figure A3 - Experimental data and modeled curves from RB-3 sample: (a) amplitude and (b) phase.

Table A3 - Fitting parameters for RB-3 sample.

\begin{tabular}{|l|l|}
\hline \multicolumn{1}{|c|}{ Dias model } & \multicolumn{1}{c|}{ Composed model } \\
\hline$\rho_{0}=78,9 \Omega m ; m=0,096 ;$ & $\rho_{0}=78,9 \Omega m ; m=0,149 ; \tau=3,0 \times 10^{-6} s ;$ \\
$\tau=3,5 \times 10^{-6} s ;$ & $\delta=0,47 ; \eta=4,50 s^{-1 / 2} ; m_{W 2}=0,078 ;$ \\
$\delta=0,45 ; \eta=5,50 s^{-1 / 2}$ & $\tau_{W 2}=1,1 \times 10^{-4} s ; c=0,27$ \\
\hline
\end{tabular}

RB-4

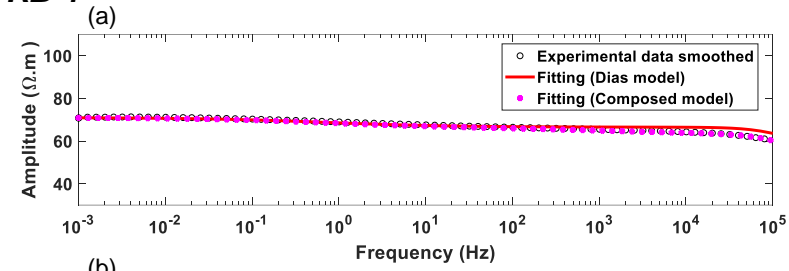

(b)

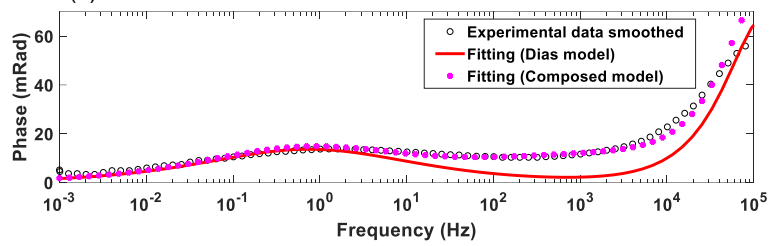

Figure A4 - Experimental data and modeled curves from RB-4 sample: (a) amplitude and (b) phase.

Table A4 - Fitting parameters for RB-4 sample.

\begin{tabular}{|l|l|}
\hline \multicolumn{1}{|c|}{ Dias model } & \multicolumn{1}{c|}{ Composed model } \\
\hline$\rho_{0}=71,0 \Omega m ; m=0,185 ;$ & $\rho_{0}=71,0 \Omega m ; m=0,240 ; \tau=3,6 \times 10^{-6} s ;$ \\
$\tau=3,4 \times 10^{-6} s ;$ & $\delta=0,72 ; \eta=3,00 s^{-1 / 2} ; m_{W 2}=0,053 ;$ \\
$\delta=0,70 ; \eta=3,2 s^{-1 / 2}$ & $\tau_{W 2}=1,1 \times 10^{-4} s ; c=0,42$ \\
\hline
\end{tabular}

Appendix B - Relaxation time distribution curves of Campos Basin (CB) and Recôncavo Basin (RB) rock samples

CB-1
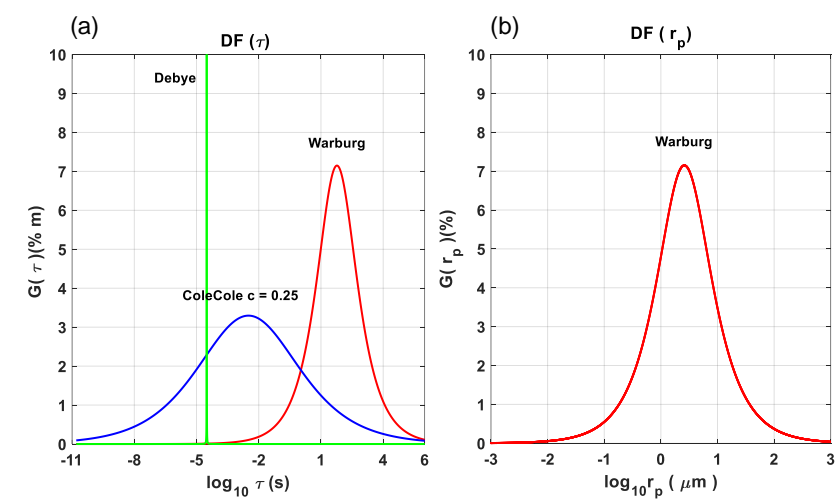

Figure B1 - Distribution function curves from CB-1 sample: (a) relaxation times distribution and (b) pore radius/throat distribution.

CB-2
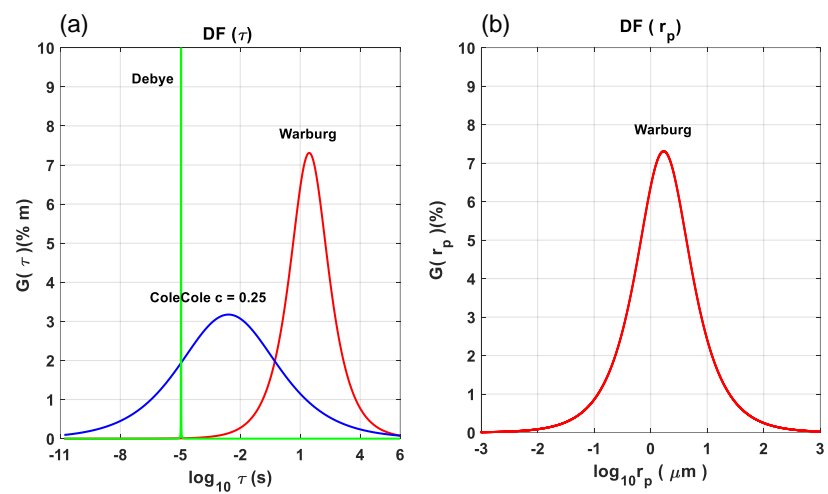

Figure B2 - Distribution function curves from $C B-2$ sample: (a) relaxation times distribution and (b) pore radius/throat distribution.

\section{CB-3}
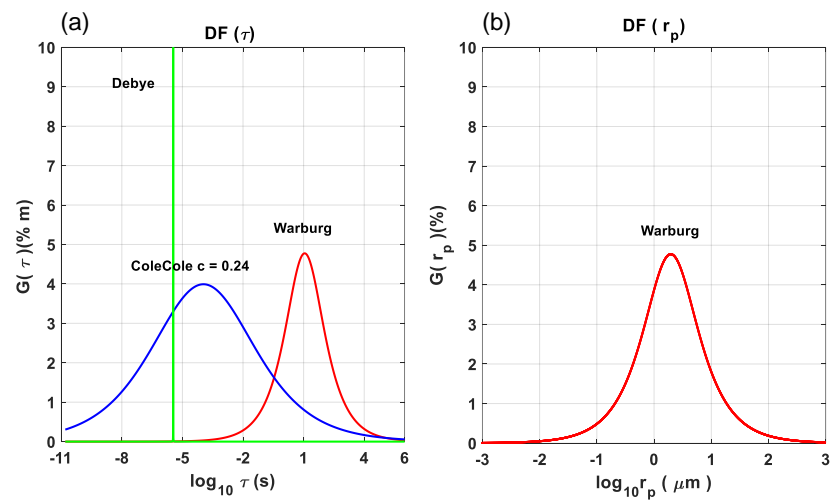

Figure B3 - Distribution function curves from CB-3 sample: (a) relaxation times distribution and (b) pore radius/throat distribution. 
CB-4
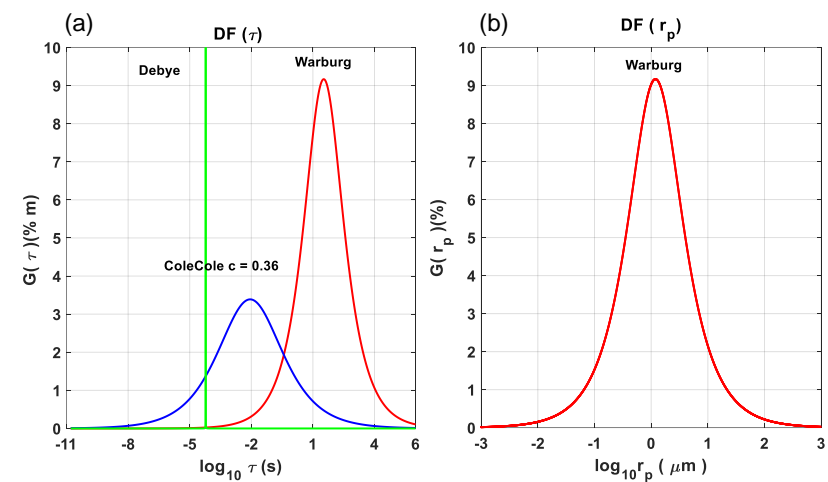

Figure B4 - Distribution function curves from CB-4 sample: (a) relaxation times distribution and (b) pore radius/throat distribution.

$R B-1$
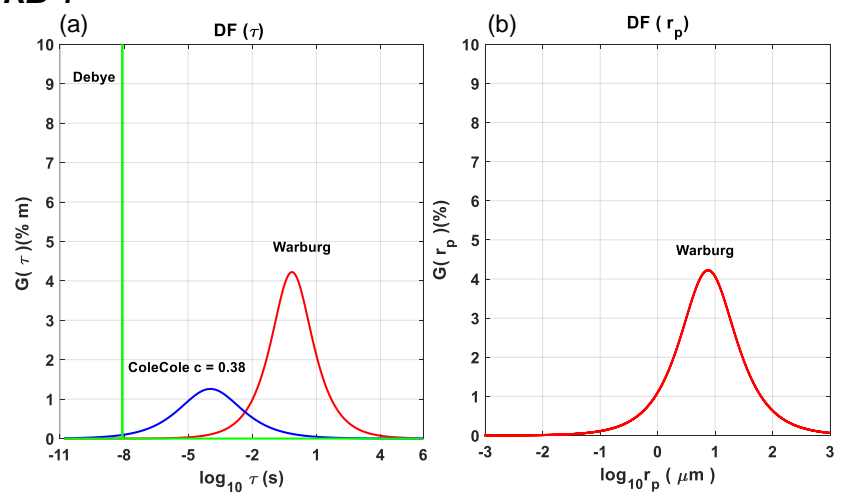

Figure B5 - Distribution function curves from RB-1 sample: (a) relaxation times distribution and (b) pore radius/throat distribution.

RB-2
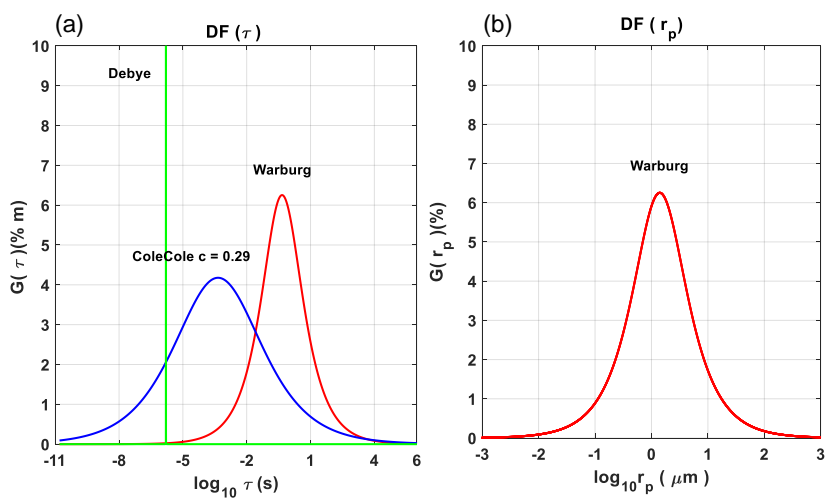

Figure B6 - Distribution function curves from RB-2 sample: (a) relaxation times distribution and (b) pore radius/throat distribution.
RB-3
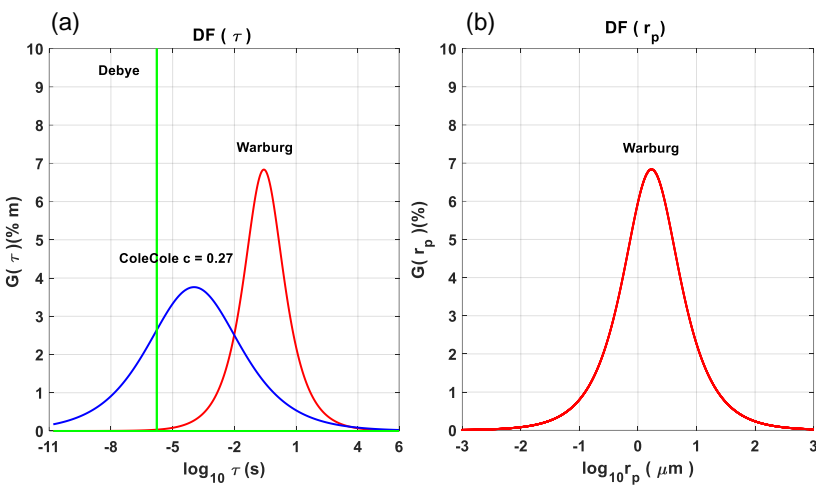

Figure B7 - Distribution function curves from RB-3 sample: (a) relaxation times distribution and (b) pore radius/throat distribution.

\section{$R B-4$}
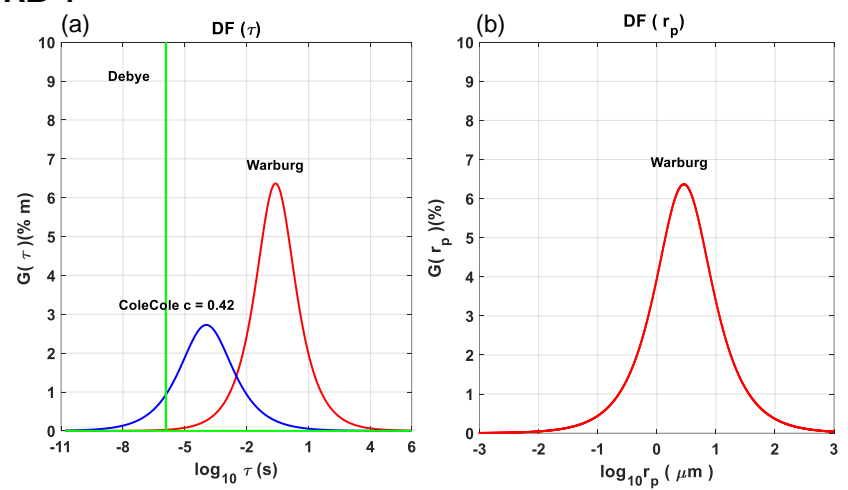

Figure B8 - Distribution function curves from RB-4 sample: (a) relaxation times distribution and (b) pore radius/throat distribution. 